\title{
IDEAS ESTÉTICAS DE LOS PLÁSTICOS DE MENDOZA (ARGENTINA) EN LA DÉCADA DE 1930. EL GRUPO GENTE DE ARTES Y LETRAS LA PEÑA
}

\author{
Esthetics ideas of artists from Mendoza (Argentina) in the 1930's. \\ La Peña group of Arts and Letters.
}

\section{Verónica Cremaschi*}

\begin{abstract}
RESUMEN
El siguiente trabajo propone abordar las ideas estéticas de distintos artistas de la provincia de Mendoza que fueron fundadores y partícipes activos del grupo denominado "La Peña". Fundamentalmente se ha intentado re- situar la obra plástica en su contexto de gestación, restituir los sentidos que la historia del arte formalista ha cercenado a muchas de las producciones locales al enfocar su estudio en su esfera eminentemente material. Es por ello que se profundiza en las visiones que tuvieron los artistas acerca de las problemáticas estéticas de su tiempo.

Resulta interesante la relación que se estableció entre los productores locales y el mundo estético de la capital Argentina, percibido como un referente ineludible pero cuestionado por los pintores provinciales.

Basándonos en documentos de la prensa local se propone revisar distintas ideas estéticas de artistas locales y explicitar la relación de las obras plásticas con las ideas que sustentaron su producción.

Palabras clave: La Peña, ideas estéticas, nacionalismo, paisajismo, organizaciones artísticas.
\end{abstract}

\begin{abstract}
This paper explores esthetics ideas of different artists from Mendoza, who integrated La Peña group. More specifically we want to understand the plastics works in the situation of creation. We try to discard the visual analysis and think the art like a product that express the epocal problematic, introducing the plastics works in the context.

For that reasons we stud the relation established between local producers and the aesthetic world of Argentina's capital. That was an unavoidable but questioned by provincial painters.

We review several aesthetics ideas through an analysis of texts published in the Mendoza province's press.
\end{abstract}

Key Words: La Peña, aesthetics ideas, nationalism, landscape painting, art's organisms.

CONICET-CCT- Mendoza. Licenciada y Profesora en Historia del Arte. Doctoranda en Historia. Argentina. Correo electrónico: vcremaschi@mendoza-conicet.gob.ar

Recepción: 18/2/2013. Aceptación: 9/12/2014. 


\section{Introducción}

Este trabajo surge a partir de la convicción de que el arte forma parte de un sistema de ideas complejo que sustenta la creación de sus formas materiales. Partimos de la premisa que es necesaria la contextualización del creador en su situación histórico cultural para otorgar sentido a sus prácticas, ya que lo consideramos un ser social que no solo influye sino que está influido por su condición contextual. Esto contradice algunas posturas románticas que, si bien han sido superadas por la historiografía nacional y latinoamericana, se observan en la tradición historiográfica provincial, la que consideran al artistas como creador original escindido de su situación y habitando en un mundo irreal formal. Por el contrario coincidimos con la opinión de Chartier quien destaca la importancia de la historia cultural como condicionante de los sujetos sociales, dicho autor interpreta "al individuo, no en la libertad supuesta de su yo propio y separado, sino en su inscripción en el seno de las dependencias recíprocas que constituyen las configuraciones sociales a las que él pertenece." (Chartier: 1992: 10)

A partir de esta consideración, es que pensamos que si bien hay una participación individual y volitiva en las acciones estéticas, el hombre es un ser de su tiempo que responde a diversos condicionantes culturales de su contexto. A su vez imaginamos que situar a una obra de arte en su medio de producción, quitándole su sentido universal, es comprenderla en su doble pertenencia: al mundo culturalsocial y al de su propia disciplina. Es por eso que abrevamos en distintos artículos de matutinos provinciales por medio de los cuales se reconstruyen parte de los debates en que se encuadraban las obras de arte.

Este trabajo propone enfocar la atención en las ideas estéticas que promediando la década del '30 sostuvieron la obra de pintores y escritores en la provincia de Mendoza, Argentina. Más específicamente analizaremos las posturas del grupo "La Peña", actuante en la provincia desde 1937.
Partiendo de la premisa de que los enunciados estéticos se encuentran enraizados en un universo mayor, ya que "una obra es eslabón en la cadena de la comunicación discursiva; como la réplica de un diálogo, la obra se relaciona con otras" (Bajtín: 1999, 265), consideramos necesario restituir a las obras plásticas del período su condición de propuestas frente a enunciados otros. Este conjunto de enunciados constituye una trama compleja de individualidades entrelazadas en discusiones, conocer sus nodos contribuye a comprender mejor el panorama de las artes plásticas de la provincia.

El interés por revisar los tópicos estéticos de los años 30 en Mendoza es un intento de restituir sentido histórico a las obras de distintos artistas. Es a partir de nuestras indagaciones que podemos afirmar que entre los artistas y escritores provinciales existió gran afición por las pesquisas regionalistas y una gran curiosidad por la figuración y el paisaje. Este interés también se observa a nivel nacional tanto en algunos artistas como en la crítica de los años '30 (Weschler, s/f: 1). Esta situación condujo a un profundo debate entre las tendencias paisajísticas y las nuevas ideas estéticas ultramarinas.

Por lo expuesto hasta aquí es que afirmamos que para comprender una obra plástica- enunciado es necesario situarla en el universo de debates estéticos de la época en que fue gestada, a partir de estas convicciones abordaremos lo sucedido en la provincia.

\section{La situación de Mendoza}

La provincia de Mendoza se encuentra al pie de la cordillera de los Andes, distante 1090 Km de Buenos Aires. Su clima semidesértico ha promovido el riego artificial por medio de las aguas de deshielo (Ponte, 2008: 11). Su actividad más tradicional y con la cual se identifica su industria, es la vitivinicultura, que incluso tiene una celebración anual que reúne a varios miles de personas en un show de nivel internacional.

La ciudad de Mendoza fue fundada en 1561, anteriormente estaba poblada por grupos 
indígenas, entre los que se destacaban los Huarpes. (Montaña, 2007: 280). Está enclavada una región agrícola históricamente vinculada a Chile, capitanía a la que perteneció hasta 1776 en que a partir de la fundación del Virreinato del Río de la Plata se integró a los territorios que conformarían Argentina. Durante la época colonial su importancia se debió a que era ciudad obligada de paso entre Santiago y Buenos Aires.

Si bien se marca como un hito la unificación de Mendoza al Virreinato del Río de la Plata, dicha integración no se dio de manera efectiva hasta la llegada del ferrocarril en 1885. Este medio de transporte intensificó la relación de la provincia con la capital de la Argentina y facilitó el fluir de ideas entre Buenos Aires y Cuyo. Esta región está ubicada en el centro oeste de la República Argentina, abarca, tradicionalmente, las provincias de Mendoza, San Juan y de San Luis, éstas comparten cierta unidad cultural y una tradición histórica en común.

A partir del impulso modernista que trajo el ferrocarril se produjo una mayor integración entre las provincias que conformaban el país. Buenos Aires, ciudad cosmopolita y portuaria, se encargó de esparcir las nuevas ideas que llegaban allende el mar por todo el territorio mediante los nuevos medios de transporte.

La distancia geográfica que separa a la provincia con Buenos Aires creó un intercambio dispar en lo que a ideas estéticas se refiere, lo que le otorgó a Mendoza cierta individualidad que se acentuó con la importancia de los regionalismos en la década del '30.

Durante estos años se hizo patente la tensión existente entre los artistas provinciales y su relación con la capital argentina. Esta tensión oscilaba entre una necesidad de consagrarse y mostrar sus ideas en el ámbito porteño y la fuerte convicción de mantener las características que los distinguían de la capital y les otorgaban un sello particular a sus creaciones estéticas.

Políticamente el período de 1930-43 estuvo signado por lo que se ha denominado la "Restauración Conservadora" o el "Neoconservadurismo" (Cueto et alt., s/f.: 4). Más precisamente, en Mendoza llegó al poder un grupo que participaba de la ideología conservadora y que era conocido con el nombre de Partido Demócrata, vulgarmente denominado los gansos.

El resurgimiento de esta línea política estuvo en manos de ex integrantes del partido Liberal, en general se trataba de políticos que provenían de familias tradicionales de Mendoza o de inmigrantes prósperos que se habían posicionado socialmente gracias a los títulos universitarios obtenidos en distintas universidades nacionales (Bracheta et alt., 2011: 126).

Los gansos en Mendoza, haciéndose eco de las ideas neoconservadoras a nivel nacional, tuvieron un programa basado en la eficacia de la obra pública, la intervención y regulación en la producción vitivinícola (de gran importancia en la región), la estructuración y especialización de la administración pública, y el buen manejo presupuestario (Caroglio, 2009: 93). Los gobiernos Demócratas se caracterizaron por instituir el fraude electoral como forma de alcanzar el poder político en los comicios (Ibíd.: 96). Este mecanismo para fraguar las elecciones, denominado por ellos mismos con el eufemismo de "fraude patriótico", caracterizó los períodos electorales de toda la década del ' 30 , por lo que se la conoce con el nombre de "década infame".

Si bien se distinguen dos facciones dentro del Partido Demócrata, una más liberal y laica (blanca) y una conservadora católica (Satlari, 2004: 306) ambas estuvieron signadas por el fuerte nacionalismo que caracterizó el período.

En el mencionado contexto político y bajo las condiciones geográficas antes indicadas, surgió en la provincia una conciencia regional, influenciada por el sello nacionalista de los gobiernos actuantes de la década.

En este sentido aparecieron nuevas tendencias estéticas tanto literarias como plásticas, que concentraron su interés en lo local, pero manifestado a partir de distintas expresiones formales. Algunas de ellas tuvieron en cuenta los lenguajes innovadores de las nuevas tendencias. Así es que, por ejemplo, en el ambiente literario se desarrollaron escuelas bajo un ropaje formal vanguardista y sencillista pero siempre con un decidido contenido 
nacionalista (Roig, 1966:51). Este contenido fue expresado a través de un temario en que se destacaron la búsqueda del paisaje natural y del paisaje humano de la región, entendida ésta como una realidad de tiempo y espacio con tradición y territorio propio (Ibíd.). Algunas de las características mencionadas también se aprecian en las obras plásticas de los pintores del momento. La tradición paisajística tenía una larga trayectoria en la región, Fernando Fader (1882- 1935) resulta un exponente muy importante de esta escuela durante la generación anterior. Este pintor se radicó en la provincia durante más una década e influyó en la nueva camada de pintores. Es interesante percibir que durante los '30 este género se sustenta sobre distintos debates generados a partir de las innovaciones plásticas más radicales.

\section{Agrupaciones de Mendoza}

En un escenario plagado de cambios, dentro de una ciudad en continuo crecimiento y luego del fuerte impacto de las olas inmigratorias que se sucedieron en su mayor escala hasta principios del siglo XX, comenzaron a gestarse una serie de ideas tendientes a organizar a los nuevos artistas y escritores que ya sumaban un buen número en la región. Es así que, a comienzos de los '30, en la provincia de Mendoza surgieron los primeros intentos de agruparse por parte de los hacedores culturales.

Esta situación, se generó en como un intento de institucionalización de distintas actividades culturales que se estaban llevando a cabo en la provincia. También, para la época, se dieron los primeros pasos hacia el reconocimiento de artistas y escritores como trabajadores en ámbitos de la cultura, intención que se manifestó en la organización de asociaciones con características de gremios.

Es así que, sin apoyo oficial, comenzaron a gestarse distintas agrupaciones que fueron clave en la organización y difusión de las ideas estéticas regionales, entre otras se destacan la Academia Provincial de Bellas Artes y La Asociación Cultural de Extensión Artística al
Aire Libre, ambas de 1933. Éstas surgieron como una tentativa, propuesta por parte de los artistas, de democratizar el acceso a las artes a distintas clases sociales y, de esta manera, popularizar y difundir su enseñanza.

Acompañando este auge de las actividades culturales en el ámbito de las artes plásticas, tuvieron nacimiento distintas instituciones que agrupaban a artistas visuales, músicos, escritores, así por ejemplo se destaca el surgimiento, a fines de 1933 y comienzos del 1934, del "Círculo de Escritores", además se instituyó en "Primer Salón del Poema Ilustrado Mendocino", inaugurado en 1935. En este certamen participaron artistas y escritores en forma asociada enviando un poema con una ilustración incorporada, los trabajos luego fueron expuestos al público. También se destacan la creación de la "Asociación de Artes y Letras" en 1934 y el "Primer y Segundo Congreso de artistas y escritores de Cuyo" en 1937 y 1938 respectivamente. (Roig, 1965: 28, 29, 30, 31).

Los distintos productores estéticos de la época participaron simultáneamente en las instituciones, asociaciones y congresos antes nombrados.

Todas estas actividades culturales nuclearon artistas y escritores bajo el sello común de la búsqueda de la expresión con una impronta regional cuyana, basada en el paisaje y las costumbres locales. Este fuerte lazo que unía a representantes de ambas actividades fue estratégico al momento de aunar fuerzas para conseguir distintos objetivos comunes. Sumado a ello, el agruparse en estas instituciones permitió la circulación y el debate de ideas que sirvieron para encontrar destinos estéticos afines.

Las reuniones propiciaron, además, el impulso de medidas que permitió posicionarse con un criterio regional frente a la gran influencia que, en materia estética, emanaba por entonces Buenos Aires. La capital, con una realidad portuaria y cosmopolita, era propulsora de muchas nuevas tendencias en el ámbito de las artes y la cultura.

En este contexto histórico signado por la organización de los artistas e intelectuales mendocinos, surgió el grupo conocido como 
Asociación de Gente de Artes y Letras "La $P e \tilde{a}{ }^{\prime}$ ", que específicamente aglutinaba a artistas plásticos, músicos y escritores quienes se reunían periódicamente y compartían recitales, cenas, agasajos, etc.

Según el periódico La Libertad de 1938 "La Peña" reunía "en su seno a caracterizadas figuras de nuestro ambiente artístico y a un selecto núcleo de "dilettantes"[sic.] y aficionados." (F.L.V., 1938: s/p)

Inicialmente este grupo surgió haciéndose eco de su homónimo fundado en Buenos Aires (Gómez de Rodríguez Britos, 2001: 39) y que funcionaba en el mítico café Tortoni desde 1926. Entre los participantes de la Peña del Tortoni se encontraban Alfonsina Storni, Juana de Ibarbourou, Arturo Rubinstein, Conrado Nalé Roxlo, Ricardo Viñes, Roberto Arlt, José Ortega y Gasset, Jorge Luis Borges. También participaron los artistas plásticos Molina Campos, Luis Perlotti, Quinquela Martín, entre otros. El grupo, que compartía festejos, agasajos y recitales, estaba constituido por colaboradores de distintas disciplinas, característica que inspiró también al grupo de Mendoza. La idea de crear un grupo similar en la provincia habría llegado por medio de los constantes viajes de artistas locales a la capital.

"La Peña" mendocina realizó su primera reunión en la Academia de Bellas Artes el 30 de agosto de 1937 y propuso como sede el Museo Provincial de Bellas Artes.

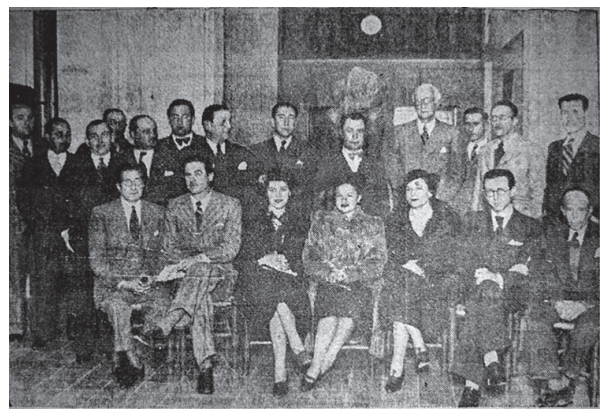

FIGURA 1

Primera reunión del grupo "La Peña"

Posteriormente, en septiembre de 1938 su nuevo local fue oficialmente inaugurado, con presencia del gobernador de la provincia, en el subsuelo de un bar-restaurant situado en pleno centro de Mendoza llamado Maxim. El funcionar en un sótano, característica que compartía con su homónima porteña, le dio independencia de los organismos gubernamentales y permitió que se desarrollaran sus actividades culturales de manera autogestiva.

Dentro de las labores llevadas a cabo por la asociación, el escritor y crítico de arte Lucio Funes destacaba en 1939 la acción de la Asociación en el campo de la música. Para entonces en la provincia no existían academias o ateneos gratuitos especializados en esta disciplina, como un paliativo a esta situación "La Peña" organizaba periódicamente distintos conciertos y audiciones que comprendían música popular, folklórica y clásica. Estos certámenes eran tan exitosos que en la nota Funes afirmaba que "su salón va resultando por demás reducido para contener al numeroso público que concurre a ellas". (Funes, 1939: 10) El programa era muy variado y en una sola noche de audición se podían interpretar piezas de López Buchardo, Albeniz, Wieniawsky, Jerikinson y Brahams, así como canciones populares españolas. ( $\mathrm{La}$ Libertad, 1939: 11).

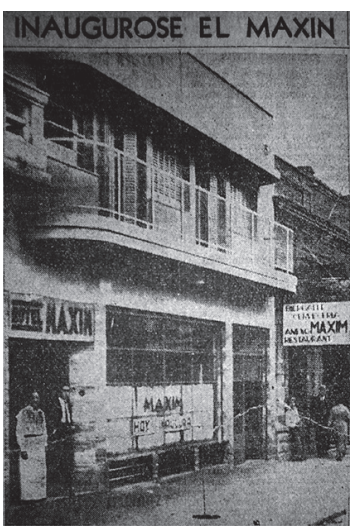

FIGURA 2

Frente del bar- restaurant Maxin, en cuyo subsuelo se reunía "La Peña"

Además de los conciertos, por lo general las tertulias incluían una disertación sobre algún artista regional del pasado a cargo de algún estudioso y la declamación de poesías locales o nacionales. Coronaba la velada la cena de rigor llevada a cabo en el salón del Maxim. 
Es destacable la participación femenina en estos encuentros, si bien muy pocas de las colaboradoras pertenecían al mundo de las artes plásticas, sí hay un gran número de intérpretes musicales o de declamadoras. Esta alta intervención se aprecia claramente en las fotografías de las cenas, algunas de las damas concurrentes eran esposas de miembros de "La Peña", sin embargo es notorio la concurrencia de solteras, lo que denota un cambio importante en relación al papel de la mujer como partícipe activa e independiente en este tipo de eventos culturales.

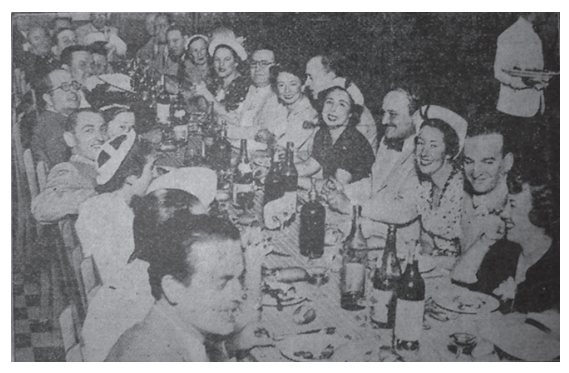

FIGURA 3

Agasajo a artistas del grupo "La Peña”.

\section{Algunas ideas del Grupo La Peña}

Retomemos ahora algunas de las ideas estéticas que se gestaron al calor de estas reuniones y que se manifestaron en la voz de algunos de los participantes del mundo de las artes plásticas.

Paradójicamente, frente a las coincidencias con la agrupación porteña (reunir a artistas, escritores y músicos, funcionar en la esfera extra oficial en un café), existió durante los '30 una tensión muy fuerte entre los artistas regionales y algunos sectores más rupturistas de las artes plásticas de la capital. Esta tensión se relacionaba con la reticencia de muchos artistas provinciales a aceptar las novedades estéticas más radicales que se producían en el ámbito porteño desde mediados de la década del ' 20.

Este desdén se aprecia desde la llegada de las influencias de las vanguardias europeas al ámbito nacional, y se transmitía mediante alusiones descalificantes a los lenguajes novedosos que ellas encarnaban. La mencionada situación se observa en la prensa mendocina a partir de distintas notas en tono sarcástico o, inclusive, a través del humor gráfico.

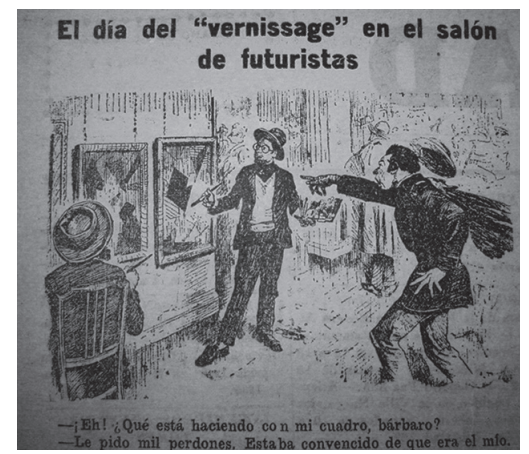

FIGURA 4

Caricatura sobre la vanguardia

Además de estas críticas peyorativas no se percibe en las distintas notas del periodismo local un reconocimiento fehaciente de los distintos movimientos que componían la vanguardia europea. Los reporteros, en algunas ocasiones, llegaban a confundir el surrealismo con el futurismo. Las actitudes antes citadas nos hablan de una falta de interés por conocer en profundidad estos nuevos lenguajes plásticos.

Otra característica que denota el desconocimiento, se manifiesta en el uso del vocablo "futurismo" para denominar a cualquiera de los lenguajes rupturistas encarnados en las tendencias vanguardistas.

Esta situación también se evidencia en un reportaje radiofónico realizado a Fidel De Lucía, uno de los exponentes más activos de La Peña, a propósito de una exposición realizada en la capital argentina, específicamente en la galería Nordiska Kompaniet. El artista opinaba que " $\mathrm{La}$ tendencia actual de la pintura en Buenos Aires, a la que se vienen plegando gran parte de los artistas porteños, va tomando el carácter de una epidemia, de la que pocos se salvan." (La Libertad, 1935: s/p) Nótese el uso de la palabra epidemia, que implica una fuerte connotación negativa y que, además, alude al hecho de la rápida dispersión de las ideas novedosas 
ultramarinas en el ámbito metropolitano. El artista agregaba:

Si en el fondo este movimiento de disconformidad con las fórmulas añejas tiene una lógica razón de subsistencia, por lo que aspira a renovar, también es cierto que la tan mentada virtud atribuida a lo que se ha dado en llamar modernismo, ha sido prácticamente falseado por extremismos desorbitados e incalificables. Los éxitos fáciles y ruidosos han deslumbrado a muchos, que como mariposas alrededor del candil, han terminado por caer en la llama, claudicando su más íntimo sentir. (Ibíd.)

El autor proponía, a diferencia de los extremismos y los éxitos fáciles que detectaba en Buenos Aires, una estética menos rupturista, en la que no se resignara a la propia esencia ya que esta "crisis del arte", tal como la designaba De Lucía, conduciría a la autodestrucción de nuestro ser nacional, de nuestra identidad propia.

Frente a este encantamiento letal producido por las tendencias extranjeras novedosas que criticaba a Buenos Aires, De Lucía proponía una vuelta al arte nacional, mirando lo propio, que él interpretaba intrínseco al paisaje y a los tipos humanos de los puntos más aislados de la nación.

Por eso consideraba que nuestra propuesta estética nacional " $h a$ de venir de tierra adentro, precisamente porque en el interior del país se conserva con más pureza la tradición de la tierra" (Ibíd.). Encontramos en estas palabras una legitimación del arte de las provincias que, según la visión de De Lucía, permanecía incontaminado frente a las influencias extrañas que circulaban en la capital porteña. La distancia habría preservado a los artistas locales de tomar caminos plásticos que los alejaran de las búsquedas propias. La influencia de este autor en sus contemporáneos y las generaciones venideras puede deducirse debido a su activa participación en los ámbitos de formación, ejemplo de ello es que fue uno de los fundadores y profesores de la Academia Provincial de Bellas Artes.

En este contexto de rechazo a las influencias extranjeras y de falta de adhesión a las estéticas importadas más rupturistas, es destacable la repercusión de la visita a la provincia del poeta, pensador y creador del manifiesto Futurista, Benito Tomaso Marinetti. Éste había sido invitado a la provincia por la colonia italiana de residentes en Mendoza (La Libertad, 1936 c: s/p). Su visita despertó interés, más que nada, en el ámbito político y repercutió como un acontecimiento social. Ello se evidencia en que, tanto las entrevistas realizadas como la conferencia que dio en el Teatro Independencia, giraron en torno a su figura como representante de las ideas fascistas italianas más que como creador de las ideas estéticas rupturistas impulsadas por el Futurismo. Muestra de ello es que la disertación que ofreció en el mencionado teatro, versó sobre la guerra de Abisinia, la cual narró en la ocasión como un testigo presencial.

Según testimonios recogidos por el diario La Libertad: "Desbordaba de público ayer la sala del teatro independencia: La anunciada conferencia del doctor Marinetti habia conseguido captar honda expectativa no sólo en la colectividad italiana de Mendoza, sino también en nuestros círculos oficiales e intelectuales." (La Libertad, 1936 a: s/p) El claro trasfondo político- ideológico también se patentiza en el recibimiento que precedió las palabras del poeta futurista: el teatro a pleno se puso de pie y cantó la "Giovinezza" al tiempo que la multitud hacía el saludo fascista.

A pesar de la convocatoria amplia que destacaba el matutino, la visita tuvo un claro trasfondo político, no existiendo un manifiesto interés por sus ideas en la esfera de la plástica. En lo que al ámbito estético se refiere no hay referencias de sus reflexiones ni tampoco una entrevista relacionada específicamente con las ideas del movimiento Futurista.

Esta falta de interés de los artistas locales por la influencia "exterior", proveniente de Europa y de Buenos Aires, y su consecuente seguridad en las búsquedas estéticas producidas en la región, se encontraba en aparente contradicción con el esfuerzo de los artistas por ser tenidos en cuenta en la metrópoli.

La mencionada situación se manifiesta claramente en la actitud de los artistas locales pertenecientes al grupo "La Peña" quienes hicieron un gran esfuerzo, de forma particular 
y también mancomunada, por participar de los certámenes nacionales y por ser reconocidos dentro del ambiente artístico de la capital.

Durante toda la década del '30 distintas personalidades, que luego fueron plantel activo en "La Peña", intentaron introducir reformas para que el influjo de sus trabajos lograra reconocimiento fuera del ámbito provinciano y adquiriera proyección nacional mediante la puerta de ingreso que significaba triunfar en Buenos Aires.

La dura realidad que significaba pertenecer al interior del país era vislumbrada ya por los intelectuales agrupados en "Asociación de Artes y Letras de Mendoza" en 1934, quienes reconocían que:

Las provincias parecen no existir para Buenos Aires. Así, toda la vida literaria y artística de la república se define en torno a los valores metropolitanos. Parece primar un criterio unilateral y excluyente, cuyo resultado no puede ser otro que la injusticia y el desconocimiento [...]. Por desgracia, Mendoza es una de las provincias más ignoradas en Buenos Aires. Necesitamos que se tenga de nosotros algo más que un concepto vitivinícola. Aquí tenemos un verdadero surgimiento artístico e intelectual, por cierto no igualado por otras regiones (Los Andes, 1934: 4).

Se sumaba a esta disconformidad los números elocuentes que se manejaban entre los artistas provinciales, ya que conocían que:

\footnotetext{
de las 313 obras expuestas en el Salón [Nacional] de 1935, 245 pertenecen a artistas de la Capital Federal, 32 proceden de la provincia de Buenos aires, 23 de la provincia de Córdoba, 3 de Santa Fe, 3 de Jujuy, 2 de Territorios Nacionales, 1 de cada una, de las provincias de Mendoza, de La Rioja, y de Entre ríos y dos provienen del extranjero ( $\mathrm{La}$ Libertad, 1936 b: s/p).
}

Estos motivos impulsaron a que los artistas regionales, en la voz de Fidel De Lucía, propusieran una serie de medidas que tendían a incorporar a las provincias en el Salón Nacional, tanto por la participación con obras como por la designación de jurados con representatividad nacional. La propuesta que hicieron para constituir el antedicho jurado, contaba de tres miembros: "Uno con residencia efectiva en la capital federal. Uno con residencia efectiva fuera de la Capital federal y a no mayor distancia de 1.000 kilómetros de la misma. Uno con residencia efectiva fuera de la capital Federal y a mayor distancia de 1.000 kilómetros de la misma." (La Libertad, 1936 d: s/p). Esta designación otorgaba, según los impulsores, imparcialidad y tendía a la inclusividad de todas las provincias. Si bien estas propuestas fueron difundidas en distintos periódicos locales y generaron una carta escrita manifestando la disconformidad, no hubo mayores repercusiones al respecto.

También hubo un intento por crear nuevos focos de importancia en el ámbito artístico del interior. Ello se percibe en el proyecto que trató una comisión constituida por De Lucía, en que se impulsaría un Salón Trianual a desarrollarse en las ciudades más grandes del interior del país y cuyos premios serían subvencionados por la Dirección Nacional de Bellas Artes.

Como se percibe, esta tensión con el mundo estético de la capital produjo actitudes ambiguas en los artistas quienes pretendían consagrarse a nivel nacional pero sin resignar las características estéticas que los distinguían e identificaban. Esta situación desencadenó en el reforzamiento de lazos entre los distintos actores provinciales quienes vieron en las asociaciones una estrategia de supervivencia y difusión de sus ideas frente a las de la metrópoli.

En este sentido los congresos de artistas y escritores de Cuyo, de los que ya se ha hecho mención anteriormente, tuvieron gran relevancia ya que evidenciaron la necesidad de los artistas de nuclearse e identificarse como una región que no solo conformaba una identidad en lo geográfico sino también en lo cultural: "Tenemos una cultura que cualquiera sea el criterio con que se quiera tipificarla [...] es una realidad palpable, que conviene mantener, con optimismo y confianza, pese a los reparos que nunca faltan cuando se trabaja en obras de esta naturaleza." (Los Andes, 1938: s/p)

Estos espacios de reflexión que se abrieron en los distintos congresos y que contaron con la participación de la gente del grupo "La Peña", pregonaban la libertad estilística convencidos que a pesar de "las diversas tendencias estéticas 
a que responden los escritores, músicos y artistas [...] se sienten unidos por el afán de creación artística y por su amor al terruño." (Ibíd.)

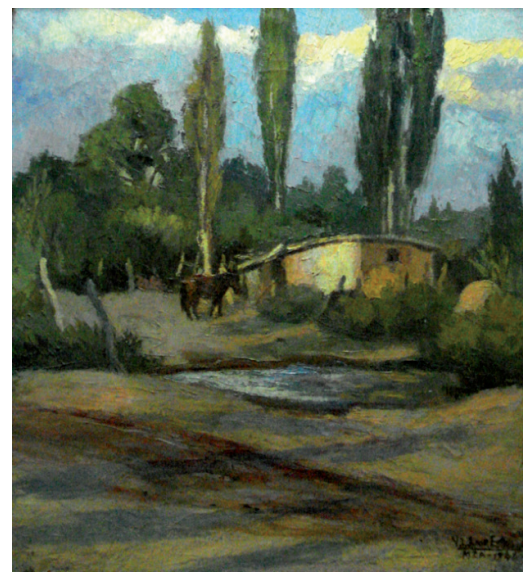

FIGURA 5

"Vivienda humilde" Estrella, Vicente Lahir. 194

El amor al terruño y la preponderancia del paisaje, parece haber sido un tópico muy fuertemente compartido por los artistas regionales en general y por los integrantes de "La Peña" en particular.. Un ejemplo de esto queda demostrado en la necesidad de acercamiento a la naturaleza que se evidencia en la radicación de Azzoni durante cinco años en los cerrillos de Tupungato, en el Valle de Uco. Esta característica, también se percibe en las ideas impulsadas por Lahir Estrella, quien dio una gran importancia a la formación de alumnos el aire libre, buscando despertar la curiosidad frente a la naturaleza, y de esta manera evitar los clichés de las tendencias imaginativas que no tenían que ver con la propia tierra (Chiavazza, 2010). De su autoría es, además, la iniciativa de construir un Solar del Artista que refugiara a los pintores de paisaje en las serranías del Challao, cercanas a la ciudad de Mendoza.

Sin embargo, este interés por el paisaje, que también abarcaba los tipos humanos, no fue plasmado en las telas de una forma naturalista y objetiva. Sino que era valorada la subjetividad del artista que al encontrarse en comunión con la naturaleza la miraba con ojos propios y plasmaba su sello personal en la materialización de la obra plástica. Ello se observaba con mucha claridad en la postura de Azzoni, para quien el paisaje cobraba importancia en la subjetividad de quién lo percibía, ya que para él el valor "denso, el importante, el verdadero, es el que surge solamente cuando se ha ahondado, cuando se ha interpretado. Al convivir, al escudriñar, lo exterior desaparece y lo interior fluye. La pintura, pues, nuestra pintura, tiene que ser más profunda, menos telúrica."(Los Andes, 1940: 10).

El artista, en este sentido, era concebido un revelador de las verdades de la naturaleza y el paisaje ya que mostraba lo "real", lo que estaba tras el velo de las imágenes materiales para descifrar los secretos herméticos del entorno. A causa de ello a Azzoni la crítica lo tildaba de "profundo conocedor del paisaje mendocino; más aún, como un intérprete de sus caudales esotéricos." (Ibíd.)

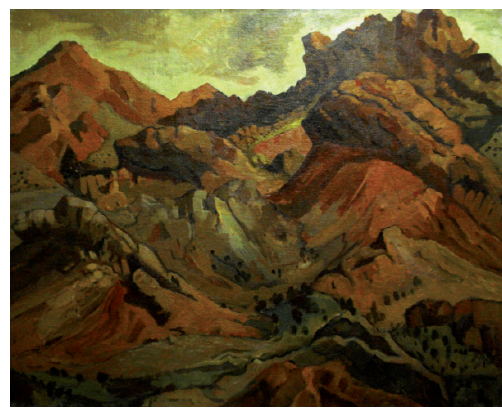

FIGURA 6

"Cerros y rocas coloradas". Azzoni, Roberto

La misma característica reconocía $\mathrm{La}$ Libertad en otros integrantes de la agrupación, como por ejemplo en De Lucía, quien según la prensa plasmaba el "paisaje como un estado del espíritu [...] no se limita a la copia fiel de la realidad sino que a fuerza de humanizado tiene una palpitación del alma del artista." (La Libertad, 1935: s/p)

Otra de las particularidades valoradas a nuestros pintores provinciales fue la de manejarse con "veracidad". Ésta no era concebida con un sentido naturalista objetivo sino como la capacidad de representar la realidad sin utilizar las artimañas de los artistas metropolitanos, he aquí otra referencia peyorativa a las nuevas tendencias. Apoyando estas ideas se destacaba 
que la pintura de Cubillos: "es una demostración cabal de cómo, sin contorsiones y sin "trucos" estéticos, se puede realizar siempre una obra de belleza, por los caminos seculares del arte, mejores en todo caso que los atajos de extraviado y pretencioso modernismo"(Lupi, 1930:8).

En similar dirección De Lucía proponía la liberación de lo artificioso característica que se adquiría cuando se empleaba el arte de vanguardia, por ello cuando se le preguntaba acerca de su credo artístico alegaba: "creo en el arte puro y noble, libre de todo "ismo", tan en boga en nuestra época. En un arte sincero cuya finalidad sea el más alto ideal y que refleje claramente nuestra personalidad y nuestro sentir"(La Libertad, 1935: s/p).

Este amor al paisaje y al terruño, y el rechazo a la utilización de los lenguajes foráneos novedosos continuó durante toda la década, así como también las reuniones de "La Peña" cuya última noticia de su existencia figura en el diario La Libertad el 11 de octubre de 1943. Consideramos que la creación de instituciones más formalmente constituidas, como la escuela de Bellas Artes de la Universidad Nacional de Cuyo y la apertura de la sede de la Sociedad Argentina de Artistas Plásticos en 1941, contribuyeron a su desaparición.

\section{Conclusiones}

Con el siguiente artículo hemos pretendido contribuir al conocimiento de las ideas estéticas que circulaban a través de la prensa mendocina en la década del '30. Nuestro cometido principal ha sido contextualizar la obra de arte producida por los artistas de la provincia.

Este respaldo en documentos escritos facilita la comprensión de los enunciados estéticos de los artistas, debido a que las fuentes contribuyen a establecer el contexto ideológico en que las obras fueron gestadas. Esto facilita la reinserción de las producciones plásticas en un universo discursivo mayor que les otorga sentido.

Si descartamos la concepción romántica que considera al arte como un lenguaje universal, comprenderemos que resulta muy difícil aprehender los significados de una obra plástica correspondiente a una situación históricotemporal diferente a la que estamos inmersos. Esta dificultad se aminora si recurrimos a distintas fuentes que nos den pistas acerca de las producciones. Es por ello que consideramos necesaria la revisión de los documentos y vestigios para intentar restituir algunos de los valores originarios de las obras plásticas.

Entendemos, siguiendo la postura de Macherey, que los sentidos de las producciones no están en la obra misma "sino al lado de ella: en sus márgenes, en ese límite donde deja de ser lo que pretende ser, porque allí está referida a las condiciones de su posibilidad." (Macherey. 1980: 399) Por ello resulta imprescindible intentar, aunque resulte complicado y esquivo, situar la obra en un contexto para poder apreciar ese "margen" de mutua influencia entre obra y realidad exterior.

Con esta intención abordamos el caso de algunos representantes de "La Peña", lo que nos permitió evidenciar la tensión existente entre los artistas provinciales y la capital argentina y el apego al paisaje como un tópico para canalizar los problemas de la identidad nacional, muy en correspondencia con la situación histórica.

Sumada a las propuestas anteriores se agrega la necesidad de los artistas de ser reconocidos y difundir sus ideas al gran público, a organizarse como región para que sus propuestas estéticas ganaran fuerzas, entre otras.

Este trabajo, además, ha pretendido ser una colaboración para aquellas regiones en que los artistas no elaboraron manifiestos ni hicieron públicas teorías escritas sistemáticamente. El acudir a fuentes no especializadas como periódicos, revistas o diarios ha resultado útil para conocer algunas de las ideas que los artistas debatían en aquel momento. Si bien estas ideas no están transmitidas de forma metódica ni expositiva, el recurrir a fuentes alternativas puede facilitar tener un panorama general de los tópicos estéticos más relevantes de un momento determinado de las historias regionales. 


\section{Nota}

1. Emplearemos el término vanguardia, para referirnos a aquellos lenguajes modernistas más rupturistas, con evidente influencia europea. Seguimos esta postura debido a que en ninguno de los artículos hallados durante el período tratado este vocablo es empleado para definir el arte local, al que si se aplica frecuentemente el adjetivo "moderno".

\section{Bibliografía citada}

Bajtin, Mijaíl. (1999). Estética de la producción verbal. México: Siglo XXI.

Bracheta, María et alt. (2011). Te contamos una historia de Mendoza (de la conquista hasta nuestros días). Mendoza: EDIUNC.

Caroglio, Ana. (2009). «Las contiendas electorales bajo la égida demócrata, Mendoza, 1931-1937.» En Estudios, no 22 (primavera): 75- 104.

Chartier, Roger. (1992). EL mundo como representación. Madrid: Gedisa.

Chiavazza, Pablo. (2010). «Vicente Lahir Estrella y su rol en la construcción del moderno campo artístico mendocino.» En El ojo de la época, de Pablo Chiavazza et alt. Mendoza: ECA, 51- 62.

Cueto, Adolfo et al. s/f. «Historia de Mendoza Fascículo 5.» En Historia de Mendoza, de A. Cueto, A. Romano y P. Sacchero. Mendoza: Los Andes.

FLV. 1938. «Notas de Arte. El festival de "La Peña".» En La Libertad, 31 de octubre. Mendoza. s/p

Funes, Lucio. «El Arte en Mendoza.» En Los Andes, 21 de mayo de 1939. Mendoza. p. 10.
Gómez de Rodríguez Britos, Marta. 2001. Mendoza y su arte en la década del 30'. Mendoza: Facultad de Filosofía y Letras. U.N.Cuyo.

La Libertad. 1935. «El éxito de la nueva exposición de Fidel De Lucía en Buenos Aires.» 3 de junio . Mendoza. s/p

1936 a. «El espíritu de la Nueva Italia venció en África Oriental.» 14 de septiembre.Mendoza. $\mathrm{s} / \mathrm{p}$

1936 b. «El Salón Nacional debe acoger a todos los artistas del país.» 25 de septiembre. Mendoza. p. 4.

1936 c. «Hoy llega a Mendoza el creador del Futurismo.» 12 de septiembre. Mendoza. s/p

. 1936 d. «Reformas al Reglamento del Salón Nacional de B. Artes .» 15 de septiembre. Mendoza. s/p

. 1939:«Notas de Arte. La fiesta de hoy en La Peña.» 19 de agosto. Mendoza. p 11.

Los Andes. 1934. «Propósito que persigue la Asociación de Artes y Letras de Mendoza, de reciente creación.» 24 de diciembre. Mendoza. p. 4.

. 1938. «Tuvo lugar ayer en San Juan la sesión inaugural del Congreso de Artistas y Escritores de Cuyo.» 11 de sptiembre. Mendoza. p. 4.

1940. «Valorable es la labor que lleva cumplida R. Azzoni.» 25 de diciembre. Mendoza. p. 10.

Lupi, A. 1930. «Un juicio crítico sobre el pintor Rafael Cubillos.» En: Los Andes, 13 de enero.Mendoza. p. 8. 
Macherey, Pierre. 1980. «La cuestión crítica.» En Estética y Marxismo. comp. Adolfo Sánchez Vázquez, 394-400. México: Era.

Montaña, Elma. 2007. «Identidad regional y construcción del territorio en Mendoza (Argentina): memorias y olvidos estratégicos.» Bulletin d l'Institut Francais d'Études Andines, 36(2), 277-297.

Ponte, Jorge Ricardo. 2008. Mendoza, aquella ciudad de barro. Mendoza: CONICET.

Roig, Arturo. 1966. Breve historia intelectual de Mendoza. Mendoza: Ediciones del Terruño.

1965. La literatura y el periodismo mendocinos entre los años 1915- 1940. A través de las páginas del diario "Los Andes". Mendoza: UNCuyo.

Satlari, María Cristina. 2004. «El estado de bienestar (1918- 1955).» En Mendoza a través de su Historia, de Arturo Roig et alt., 289-334. Mendoza: Caviar Bleu.
Weschler, Diana. s.f. «Paisaje, crítica e ideología.» CAIA. s.f. www.caia.org.ar/ docs/37-Wechsler.pdf (último acceso: 2013 de febrero de 15).

\section{Índice de Imágenes}

Figura 1. Primera reunión del grupo "La Peña". Los Andes. Mendoza. 30 de agosto de 1937. s/p.

Figura 2. Frente del bar- restaurant Maxin, en cuyo subsuelo se reunía "La Peña". Los Andes Mendoza 21 de octubre de 1937. Pág. 11

Figura 3. Agasajo a artistas del grupo "La Peña”. La Libertad. Mendoza. 16 de diciembre de 1937. S /p.

Figura 4. Caricatura sobre la vanguardia. La Libertad. Mendoza. 24 de junio de 1924. S/p.

Figura 5. "Vivienda humilde" Estrella, Vicente Lahir. 1944. $62 \times 68 \mathrm{~cm}$. Gentileza Lic. Pablo Chiavazza.

Figura 6. "Cerros y rocas coloradas". Azzoni, Roberto. $87 \times 107 \mathrm{~cm}$. Gentileza Lic. Pablo Chiavazza

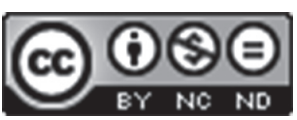

Este obra está bajo una licencia de Creative Commons Reconocimiento-NoComercial-SinObraDerivada 4.0 Internacional. 